\title{
Changes in Serum Adipocytokines and Inflammatory Biomarkers Following One-Year of Exercise Training in Obese Adolescents
}

Barbara Garanty-Bogacka1*, Monika Rać ${ }^{3}$, Małgorzata Syrenicz ${ }^{1}$, Aneta Gębala ${ }^{1,2}$, Mieczysław Walczak ${ }^{4}$ and Anhelli Syrenicz ${ }^{5}$

1/ndependent Laboratory of Propaedeutics of Children's Diseases, Pomeranian Medical University, Szczecin, Poland

${ }^{2}$ Division of Paediatrics, Gastroenterology and Rheumatology of the Zdroje Clinic in Szczecin, Poland

${ }^{3}$ Department of Biochemistry and Medical Chemistry Pomeranian Medical University, Szczecin, Poland

${ }^{4}$ Department of Paediatrics, Endocrinology, Diabetology, Inborn Errors of Metabolism and Cardiology Pomeranian Medical University, Szczecin, Poland

${ }^{5}$ Department of Endocrinology, Metabolic Diseases and Internal Diseases, Pomeranian Medical University, Szczecin, Poland

\begin{abstract}
Background: Obese individuals commonly demonstrate elevated levels of serum inflammatory markers and cell adhesion molecules. The later are known to be implicated in the pathogenesis of cardiovascular disease. Increased physical activity has been shown to be effective in altering adipocytokines, and inflammatory markers; however, little is known about the effect of exercise training alone on these parameters in children and adolescents.
\end{abstract}

Aim: This study was designed to compare the effects of moderate-intensity training and caloric restriction on serum adipocytokines as well as markers of inflammation and cell adhesion in obese adolescents.

Material and methods: Fifty six obese adolescents, participating in an obesity intervention program, were studied before and after 1 year program consisting of moderate physical activity (exercise group including 37 participants) or hypocaloric diet (diet group: 19 subjects). Highly sensitive C-reactive protein, interleukin-6, adipocyte fatty acid-binding protein-4, adiponectin, intracellular cell adhesion molecule-1 and vascular adhesion molecule-1 were measured before and after intervention. Body composition, blood pressure, fasting blood glucose and insulin were also assessed.

Results: After 1 year, a significant reduction in all adiposity parameters were observed in both groups, but the changes were more prominent in the exercise group. Physical training was also favourable compared with hypocaloric diet in reducing serum markers of inflammation $(P<0.009$ for $C$-reactive protein; $P<0.002$ for interleukin- 6$)$ and cell adhesion $(P<0.020$ for intracellular cell adhesion molecule-1; $P<0.000$ for vascular adhesion molecule- 1$)$. In addition, exercise training induced a rise of adiponectin $(P<0.000)$ and fall in fatty acid-binding protein-4 $(P<0.000)$, independent of weight loss.

Conclusions: We conclude that moderate-intensity training alone reduced blood markers of inflammation and cell adhesion in obese adolescents more than observed after caloric restriction. Exercise training was also associated with potentially favourably changes in serum adipocytokines.

Keywords: Exercise; Obesity; Inflammation; Children

\section{Introduction}

With an increasing prevalence [1], adolescent obesity often precedes adulthood obesity and is associated with increased cardiovascular morbidity and mortality [2], therefore represents a major public health problem. Since serious co-morbidities are common in obese adults, it is important to search for early markers or risk factors for cardiovascular disease (CVD) in obese youth. There is increasing evidence that obesity is associated with low-level inflammation which may be responsible for many metabolic complications of obesity [3]. Obese individuals commonly demonstrate increased levels of blood markers suggesting low-grade chronic systemic inflammation [4]. At least 24 adipokines were identified whose serum levels are enhanced in obesity, and most of them have pro-inflammatory properties [3]. The main inflammatory molecule is C-reactive protein (CRP) which is actually acute phase protein primarily secreted by the liver in response to adipokine interleukin-6 [5], and both molecules are independently associated with obesity and cardiovascular disease [6]. Interleukin-6 (IL-6) is an immunomodulatory cytokine which may exert pro- and antiinflammatory [3], as well as metabolic effects [7]. IL-6 and CRP may affect endothelial function via either direct or indirect mechanisms such as reducing production of nitric oxide and stimulating inflammationoxidative stress pathways [8].
Elevated levels of pro-inflammatory factors also appear to directly induce expression of cell adhesion molecules in endothelium and recruit of leukocytes [9], which is essential to the pathogenesis of atherosclerosis [10]. It has been found that elevated serum levels of soluble intracellular adhesion molecule-1 (sICAM-1) and soluble vascular cell adhesion molecule-1 (sVCAM-1) were associated with increased risk for coronary heart disease [11].

Pro-inflammatory state and endothelial dysfunction have generally been considered as two major mechanisms contributing to early stages and to further development of atherosclerosis $[8,10]$. Many of the pro-inflammatory and pro-atherogenic factors associated with obesity-related vascular disease in adults have also been described in

*Corresponding author: Dr. Barbara Garanty-Bogacka, Independent Laboratory of Propaedeutics of Children's Diseases, Pomeranian Medical University, Szczecin, Poland, E-mail: garbog4@wp.pl

Received July 22, 2012; Accepted August 23, 2012; Published August 28, 2012 Citation: Garanty-Bogacka B, Rac M, Syrenicz M, Gebala A, Walczak M, et al (2012) Changes in Serum Adipocytokines and Inflammatory Biomarkers Following One-Year of Exercise Training in Obese Adolescents. J Diabetes Metab 3: 212. doi:10.4172/2155-6156.1000212

Copyright: (C) 2012 Garanty-Bogacka B, et al. This is an open-access article distributed under the terms of the Creative Commons Attribution License, which permits unrestricted use, distribution, and reproduction in any medium, provided the original author and source are credited. 
children [12-14]. These included decreased adiponectin (ADN) level and increased adipocyte fatty acid-binding protein (FABP-4) level in the serum. Circulating level of adiponectin, cytokine released by adipose tissue, has been reported to be lower in human obesity and the reduction is associated with the development of obesity-related metabolic syndrome, including type 2 diabetes and atherosclerosis [15]. Adiponectin promote the production of NO in endothelial cells, and hypoadiponectinemia is associated with impaired endothelial function [16].

Compared to adult studies, the markers mentioned above were assessed in children with the exception of adipocyte fatty acid-binding protein. Adipocyte FABP is a major cytoplasmic protein in adipocytes and macrophages and is involved in the intracellular regulation of lipid metabolism, but may be also released into the bloodstream [17]. Results of many studies suggest that FABP is closely associated with insulin resistance, type 2 diabetes and atherosclerosis [17-19].

Numerous studies in obese patients have shown that even moderate weight loss through dietary changes and physical exercises is effective in preventing and managing obesity-associated disorders [20,21]. It has been postulated that aerobic exercise training reduce the risk of CVD both independently and through modification of traditional risk factors, such as hypertension, dyslipidemia, insulin resistance and type 2 diabetes [22].

It is generally accepted that the effectiveness of obesity treatment in pediatric population is unsatisfactory, especially in older children and adolescents. Only few therapeutic interventions involving adolescents have produced significant long-term weight loss [23]. As obesityassociated factors still predominate over genetic predisposition in the pathogenesis of obesity-related disorders, treatment strategies in obese children are based on changes in lifestyle, including increased physical activity and/or dietary modifications [24]. On the other hand, diet restriction and daily physical activities at the same time throughout a long period of time are not accepted by teenagers, and most of them drop-out from an obesity intervention program or choose only one method.

Therefore, the following study was performed to compare the effects of moderate-intensity physical training and hypocaloric diet on serum levels of selected adipocytokines as well as markers of inflammation and cell adhesion in obese adolescents.

\section{Patients and Methods}

The study group consisted of 56 obese adolescents ( 26 boys and 30 girls), aged 12 to 18 years, attending the Outpatients Clinic for Children with Metabolic Disorders. All patients were pubertal (Tanner stage: II - V), determined by physical examination by a pediatrician according to the criteria of Tanner. Obesity was recognized on the basis of body mass index $(\mathrm{BMI})>97^{\text {th }}$ percentile for age and sex on BMI percentile charts for Polish children and adolescents [25]. Patients with syndromal obesity, infections, cancers, autoimmunologic diseases, hormonal abnormalities as well as hepatic or renal dysfunction were excluded. None of the subjects were taking any medications, drinking alcohol or smoking cigarettes.

The protocol of this study was approved by the Ethical Committee of the Pomeranian Medical University. Written parental consent and patient assent was also obtained.

Anthropometric measurements (body weight, height and waist circumference) were measured by trained staff, with the participants wearing only light underwear and without shoes. Standard, electronic scale and wall-mounted stadiometer were used to determine body weight and height. Body mass index (BMI) was calculated by dividing weight in kilograms by height in meters squared $\left(\mathrm{kg} / \mathrm{m}^{2}\right)$. Since BMI changes with age, it is expressed as a standard deviation score - SDSBMI [25]. The minimal abdominal circumference between the xiphoid process and the iliac crest was measured using the flexible plastic tape, with the subject standing. As waist circumference changes with age, the SDS-waist circumference was also calculated [26]. Bioelectrical impedance analysis was performed in the fasted state using a fixedfrequency $(50 \mathrm{kHz})$ bioimpedance analysis analyzer (Bioelectrical Impedance Analyzer Tanita 131, Japan).

All 56 patients initially started in the one-year outpatient intervention program consisted of caloric restriction supervised by the study nutritionist, an exercise program developed by exercise physiologists and behavior therapy including individual psychological care of the child and his or her family. Nineteen patients wanted to drop out from the full-intervention program after three weeks, since they were unable to meet the time commitment to exercise at the gymnasium 5 times/week. At the same time, these patients still declared that they were ready to continue calorie restriction diet. In order to avoid the large drop-out from the study, we allowed the adolescents to choose the type of intervention (diet vs. exercise).

The dietary-treated group (diet group) was prescribed a 500-kcal deficit diet by the dietitian and received instructions in behavioral change techniques. Subjects in the diet group met with a nutritionist once in a week for 3 months after an initial baseline study, and then once in a month to the end of the study.

Remaining 37 subjects (exercise group) exercised 5 times/week (45 minutes each time) at the gymnasium under close supervision of exercise physiologist and at school 2 times/week. Each session was begun after a warm-up/flexibility exercise that consisted of progressive stretching for 5 minutes. The aerobic activity involved mainly brisk walking with movements of total body to ensure maximum caloric expenditure. Physical training was limited to 20 minutes during the first week of the study. Then, the duration of activity was progressively increased so that by the third week the participants were completing 45 minutes of activity per session. Following each training, the subjects "cooled down" by slow walking for 5 minutes. This moderate physical activity regimen was supplemented by calorie restriction by exchanging high-calorie snacks with low-sugar, low-fat snacks and limiting sugarbased carbonated drinks. Analyses of diet diaries revealed that caloric deficit was an average $100 \mathrm{kcal} /$ day in this group of patients.

Blood samples were obtained in the fasting state at 8 a.m. and centrifuged immediately. Determination of serum concentrations of C-reactive protein (CRP) was performed using a high-sensitivity assay based on immunoturbidimetric method (Olympus, J). Highsensitivity enzyme-linked immunosorbent assay (ELISA) was used for IL-6 (DiaSource, B), FABP-4 (BioVendor, CZ), sICAM-1 and sVCAM-1 (eBioscience, A). Serum adiponectin was determined by radioimmunometric (RIA KIT) test (Milipore, Mi, USA).

Glucose was measured with the glucose oxidase technique (Olympus, J). Free insulin concentration was determined by RIA (Pharmacia, A). Fasting glucose and insulin concentrations were used to calculate the homeostasis model assessment for insulin resistance (HOMA-IR) [27]. 
Citation: Garanty-Bogacka B, Rac M, Syrenicz M, Gebala A, Walczak M, et al. (2012) Changes in Serum Adipocytokines and Inflammatory Biomarkers Following One-Year of Exercise Training in Obese Adolescents. J Diabetes Metab 3: 212. doi:10.4172/2155-6156.1000212

Page 3 of 6

\section{Statistical methods}

Statistical analyses were performed using the STATA 11 software package. All data are expressed as mean and standard deviation $( \pm$ SD). Kolmogorov-Smirnov non-parametric procedure was used to confirm the normality distribution assumption for all quantitative variables. Non-normally distributed variables were log-transformed before statistical analysis.

Changes in variables were calculated as variable measured at baseline minus variable measured a year later. They are presented as mean difference change from baseline $(\Delta) \pm \mathrm{SD}$.

Correlation analysis between variables before and after intervention was done using the Pearson's correlation. Statistically significant differences were tested for quantitative items by using an independent sample $t$ test and a one-way ANOVA. For within-group analysis (the baseline vs. after intervention values) a paired Student's t test was used. For among-group comparisons, ANOVA for repeated measures was used (before and after one year intervention). Covariance analysis (ANCOVA) was performed to assess the effect of physical activity on changes in serum concentrations of adipocytokines as well as markers of inflammation and cell adhesion. ANCOVA was applied when the ANOVA interaction term was significant. A value of $P<0.05$ was considered significant.

\section{Results}

There were no significant differences between the two groups at baseline for all physical and biochemical parameters (Table 1).

At baseline, serum concentrations of FABP-4 and sICAM- 1 were significantly higher in the exercise group compared to the diet group $(33.8 \pm 13.2$ vs. $25.9 \pm 14.7 \mathrm{ng} / \mathrm{mL}, P<0.05 ; 427.8 \pm 103.5$ vs. $362.5 \pm 85.5$ $\mathrm{ng} / \mathrm{mL}, P<0.05$, respectively) while adiponectin level was significantly lower in the exercise group $(7.5 \pm 2.9$ vs. $10.8 \pm 4.3 \mu \mathrm{g} / \mathrm{mL}, P<0.01)$ as shown in table 2 and figure $1 \mathrm{~b}$.

Changes in the variables of interest in response to lifestyle
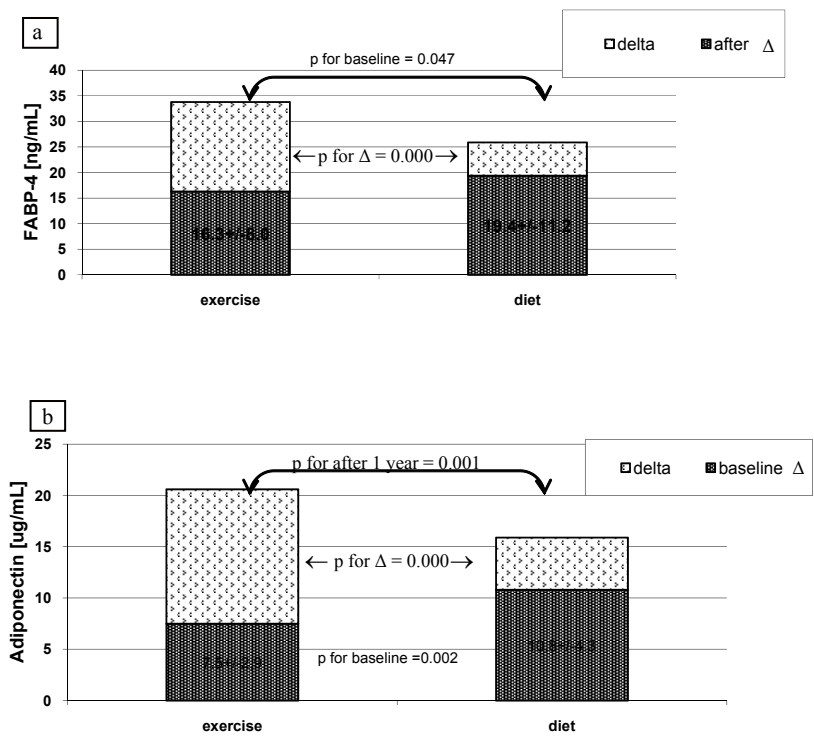

Figure 1: (a) FABP-4 concentration in exercise and diet groups before and after 1 year of intervention.

(b) Adiponectin concentration in exercise and diet groups before and after 1 year of intervention.

\begin{tabular}{|c|c|c|c|c|c|}
\hline & \multicolumn{2}{|c|}{ Exercise group } & \multicolumn{2}{|c|}{ Diet group } & \multirow{2}{*}{ P-value } \\
\hline & Baseline & Follow-up & Baseline & Follow-up & \\
\hline Age (years) & $13.6 \pm 2.7$ & $14.6 \pm 2.7$ & $14.5 \pm 2.3$ & $15.5 \pm 2.3$ & 0.221 \\
\hline Gender & \multicolumn{2}{|l|}{$54 \%$ Male } & \multicolumn{2}{|l|}{$32 \%$ Male } & \\
\hline Weight (kg) & $84.2 \pm 19.6$ & $77.2 \pm 18.6^{* * *}$ & $83.7 \pm 15.0$ & $80.7 \pm 14.8^{* * *}$ & 0.000 \\
\hline BMI (kg/m2) & $30.7 \pm 4.0$ & $27.5 \pm 4.1^{\star * *}$ & $31.3 \pm 3.6$ & $29.4 \pm 4.0^{* * *}$ & 0.002 \\
\hline SDS-BMI & $3.9 \pm 1.3$ & $2.7 \pm 1.5^{\star * *}$ & $4.1 \pm 1.3$ & $3.5 \pm 1.6^{* * *}$ & 0.001 \\
\hline Body fat (\%) & $34.6 \pm 6.7$ & $28.3 \pm 8.0^{* * *}$ & $35.5 \pm 6.5$ & $34.2 \pm 6.9^{* *}$ & 0.001 \\
\hline Waist (cm) & $101.4 \pm 11.7$ & $94.7 \pm 11.9^{* * *}$ & $103.6 \pm 11.7$ & $100.1 \pm 10.0^{* *}$ & 0.019 \\
\hline SDS-waist & $4.2 \pm 1.3$ & $3.2 \pm 1.4^{* * *}$ & $4.5 \pm 1.6$ & $4.0 \pm 1.4^{* *}$ & 0.027 \\
\hline \multicolumn{6}{|l|}{ Blood pressure } \\
\hline $\begin{array}{l}\text { Systolic blood } \\
\text { pressure } \\
(\mathrm{mm} \mathrm{Hg})\end{array}$ & $129.3 \pm 10.4$ & $107.1 \pm 8.6^{* \star *}$ & $122.8 \pm 9.5$ & $113.1 \pm 8.1^{\text {*** }}$ & 0.049 \\
\hline $\begin{array}{l}\text { Diastolic blood } \\
\text { pressure } \\
(\mathrm{mm} \mathrm{Hg})\end{array}$ & $81.2 \pm 9.8$ & $70.7 \pm 8.4^{* * *}$ & $79.3 \pm 8.3$ & $68.8 \pm 10.1^{* * *}$ & 0.963 \\
\hline $\begin{array}{l}\text { Glucose } \\
(\mathrm{mmol} / \mathrm{L})\end{array}$ & $5.1 \pm 0.4$ & $4.8 \pm 0.4^{\star \star *}$ & $5.1 \pm 0.5$ & $4.9 \pm 0.5$ & 0.154 \\
\hline $\begin{array}{l}\text { Insulin } \\
(\mathrm{pmol} / \mathrm{L})\end{array}$ & $22.9 \pm 10.1$ & $14.7 \pm 7.1^{* \star \star}$ & $19.9 \pm 5.9$ & $13.3 \pm 4.4^{* * *}$ & 0.061 \\
\hline HOMA-IR & $5.5 \pm 1.7$ & $2.9 \pm 1.7^{* * *}$ & $4.9 \pm 1.7$ & $3.2 \pm 1.2^{* * *}$ & 0.047 \\
\hline
\end{tabular}

Data are presented as mean $\pm S D$. P-value was calculated for $\Delta$ of changes ${ }^{* *} \mathrm{P}<0.01$ for within-group analysis before and after intervention ${ }^{* * *} \mathrm{P}<0.001$ for within-group analysis before and after intervention

Table 1: Clinical and biochemical parameters at baseline and after 1 year of exercise/dietary intervention.

\begin{tabular}{|c|c|c|c|c|c|}
\hline & \multicolumn{2}{|l|}{ Exercise group } & \multicolumn{2}{|l|}{ Diet group } & \multirow{2}{*}{ P-value } \\
\hline & Baseline & Follow-up & Baseline & Follow-up & \\
\hline $\begin{array}{l}\text { CRP } \\
\text { (mg/L) }\end{array}$ & $1.7 \pm 0.8$ & $0.8 \pm 0.4^{* * *}$ & $1.3 \pm 0.8$ & $0.9 \pm 0.5^{\star \star \star}$ & 0.009 \\
\hline $\begin{array}{l}\text { IL-6 } \\
\text { (pg/mL) }\end{array}$ & $2.2 \pm 0.8$ & $0.9 \pm 0.5^{\star * *}$ & $1.9 \pm 0.8$ & $1.2 \pm 0.7^{* \star *}$ & 0.002 \\
\hline $\begin{array}{l}\text { ICAM-1 } \\
\text { (ng/mL) }\end{array}$ & $427.8 \pm 103.5$ & $332.8 \pm 77.8^{\star \star \star}$ & $362.5 \pm 85.5$ & $333.0 \pm 91.9$ & 0.020 \\
\hline $\begin{array}{l}\text { VCAM-1 } \\
\text { (ng/mL) }\end{array}$ & $1033.2 \pm 318.7$ & $605.3 \pm 198.2^{* * *}$ & $860.1 \pm 305.5$ & $715.1 \pm 237.9^{\star \star \star}$ & 0.000 \\
\hline
\end{tabular}

Data are presented as mean \pm SD. P-value was calculated for $\Delta$ of changes ${ }^{* * *} \mathrm{P}<0.001$ for within-group analysis before and after intervention

Table 2: Circulating markers of inflammation and cell adhesion at baseline and after 1 year of exercise/dietary intervention.

modification in both groups (exercise and dietary group) are presented in tables 1 and 2 and figures $1 \mathrm{a}$ and $1 \mathrm{~b}$. There was a statistically significant improvement in weight, SDS-BMI, \%body fat, SDS-waist circumference, blood pressure as well as plasma insulin concentration and HOMA-IR after 1 year of lifestyle modification. Additionally, there was a significant decrease of fasting plasma glucose in the exercise group. After 1 year, a significant reduction in CRP, IL-6, FABP-4, sVCAM and increase in adiponectin in both groups were observed. There was no significant change of sICAM in the diet group. Using ANOVA to compare the changes $(\Delta)$ in the clinical and biochemical parameters among the two groups, we found statistically significant differences in all variables, except for diastolic blood pressure and fasting plasma glucose. Changes in insulin concentration tended to be higher in the exercise group after the intervention, but were not statistically significant.

The changes of circulating inflammatory and cell adhesion markers in correlation to the changes of weight status, percentage body fat, and waist circumference are shown in table 3 . In all 56 patients weight loss and decreased body fat result in significant decrease in serum levels of 


\begin{tabular}{|l|c|c|c|c|c|c|c|}
\hline \multirow{4}{*}{$\Delta$ weight } & & $\Delta$ CRP & $\Delta$ IL-6 & $\Delta$ ADN & $\Delta$ FABP-4 & $\Delta$ sICAM & $\Delta$ sVCAM \\
& $\mathrm{r}$ & 0.35 & 0.35 & -0.67 & 0.56 & 0.38 & 0.60 \\
\cline { 2 - 8 }$\Delta$ SDS-BMI & $\mathrm{p}$ & 0.008 & 0.008 & 0.000 & 0.000 & 0.004 & 0.000 \\
\hline \multirow{2}{*}{$\Delta \%$ fat } & $\mathrm{r}$ & 0.27 & 0.23 & -0.60 & 0.31 & 0.30 & 0.33 \\
\cline { 2 - 8 } & $\mathrm{p}$ & 0.040 & 0.084 & 0.000 & 0.020 & 0.026 & 0.013 \\
\hline \multirow{2}{*}{$\Delta$ SDS-waist } & $\mathrm{r}$ & 0.30 & 0.40 & -0.45 & 0.32 & 0.53 & 0.49 \\
\cline { 2 - 8 } & $\mathrm{p}$ & 0.023 & 0.002 & 0.001 & 0.018 & 0.000 & 0.000 \\
\hline & $\mathrm{r}$ & 0.27 & 0.28 & -0.37 & 0.24 & 0.48 & 0.34 \\
\cline { 2 - 8 } & $\mathrm{p}$ & 0.040 & 0.047 & 0.010 & 0.090 & 0.000 & 0.016 \\
\hline
\end{tabular}

Table 3: Changes of inflammatory and cell adhesion markers over 1-year period in correlation to changes of adiposity.

\begin{tabular}{|l|c|c|c|c|}
\hline \multirow{2}{*}{$\begin{array}{l}\text { Dependent vari- } \\
\text { able }\end{array}$} & \multicolumn{4}{|c|}{ Independent variables } \\
\cline { 2 - 5 } & \multicolumn{2}{|c|}{ exercise } & $\Delta$ of body weight \\
\hline \multirow{2}{*}{$\Delta \%$ fat } & $\mathrm{R}^{2}$ & $\mathrm{p}$ & $\mathrm{R}^{2}$ & $\mathrm{p}$ \\
\hline$\Delta$ SDS-waist & 0.05 & 0.038 & 0.17 & 0.001 \\
\hline$\Delta$ CRP & 0.04 & 0.064 & 0.16 & 0.003 \\
\hline$\Delta$ IL-6 & 0.09 & 0.042 & 0.07 & 0.054 \\
\hline$\Delta$ ADN & 0.06 & 0.047 & 0.02 & 0.234 \\
\hline$\Delta$ FABP-4 & 0.20 & 0.000 & 0.09 & 0.001 \\
\hline$\Delta$ sICAM & 0.05 & 0.037 & 0.11 & 0.003 \\
\hline$\Delta$ sVCAM & 0.01 & 0.346 & 0.06 & 0.054 \\
\hline
\end{tabular}

Table 4: Results of co-variance analysis (ANCOVA) with independent variables: exercise and $\Delta$ body weight.

CRP, IL-6, FABP-4 as well as cell adhesion molecules, whereas ADN levels significantly increased.

In the "best fit" covariance models (ANCOVA), assessing relationships between anthropometric and laboratory parameters as dependent variables with physical exercise or changes of body weight (as an independent variables), physical activity, independent of changes in body weight, led to significant improvement in serum levels of adipocytokines and inflammatory markers (Table 4 ).

\section{Discussion}

The optimal management of obesity starts with a combination of diet, physical activity, and behavioral modification. Recent studies demonstrated beneficial effects of exercise training and caloric restrictions on serum markers of inflammation and cell adhesion after weight loss in obese adolescents [28,29]. Roberts et al. [30] also showed that increased oxidative stress markers and pro-inflammatory state associated with endothelial dysfunction were normalized after shortterm lifestyle modification programme in obese children. Moreover, physical exercises are important for preserving lean body mass while dieting as well as maintaining long-term weight loss. On the other hand, this "ideal" lifestyle modification is sometimes not accepted by obese patients, especially by overweight adolescents, and it is the main reason of dropping out from intervention programs. Therefore, in this study we compared the effects of physical training and dietary restriction alone on serum levels of adipocytokines as well as markers of inflammation and cell adhesion. Our study group consisted of fifty six obese pubertal children. It is commonly accepted that puberty influences insulin resistance, inflammation and oxidative stress markers known to contribute to the development and progression of endothelial dysfunction [31]. Therefore, obese children who pass through puberty into adulthood have an increased risk of acceleration of the process of atherosclerosis [14].

The main finding of the present study is that one year of moderate- intensity training reduced elevated levels of inflammatory markers more than that observed after dietary regimen. After 1 year, the weight loss as well as improvement in other markers of adiposity was significantly higher in the exercise group compared to the diet group. Simultaneously, we found the higher reduction of blood inflammatory and cell adhesion markers in the exercise group than in the diet group. Our results are consistent with the results obtained by Tjonna et al. [32]. In this study, it has been shown that three months of twice-weekly high-intensity exercise sessions reduced fat mass and induced a more favourable changes of blood glucose, insulin and adiponectin than that observed after a traditional, multi treatment strategy, including exercise, dietary and psychological advice. Follow-up at 12 months confirmed that this protocol of exercise improved cardiovascular risk factors to a better degree than traditional obesity intervention program.

Physical activity has shown promising effects as a main therapeutic tool in obese children, especially in children with metabolic syndrome [33]. Only a few studies have evaluated the effect of exercise alone, and their results are controversial. Harmse and Kruger [34] found significant differences between serum CRP in adolescents in the different physical activity categories with lower CRP in girls in the higher physical activity group. Decreases in inflammatory factors in the group of obese adolescents who underwent 3 months physical activitybased intervention were reported by Balagopal et al. [35]. Regular exercise over 6 months has been shown to reverse vascular dysfunction associated with obesity and improve cardiovascular risk profile with significant reduction of inflammatory markers in obese adolescents [36]. It has been found that exercise training modifies body composition with initial fat loss from the viscera [37]. This would positively affect the release of pro-inflammatory factors and could explain improved cardiovascular risk profile after exercise training. In contrast to these results, Farpour-Lambert et al. [38] reported that physical activity three times/week for 3 months decreased BMI and body fat, but did not reduce serum inflammatory factors in pre-pubertal obese children. Moreover, in the absence of change in body weight, body fat and abdominal fat, exercise training alone did not improve adipokines levels [39]. These results indicate that fat reduction (especially visceral fat) is the main mechanism underlying inflammatory response after exercises. In the present study, changes of serum inflammatory and cell adhesion markers were also significantly correlated with weight loss as well as decreased body fat and waist circumference. Furthermore, we found that exercise training over one year, reduced serum levels of CRP, IL-6, sVCAM and improved adipocytokine levels independent of weight loss.

The appropriate time and intensity of exercise sessions required to obtain the beneficial effects on subclinical inflammatory state remains controversial $[32,35,36]$. It has been shown that in contrast to acute exercise, long-term exercise training reduces resting levels of most pro-inflammatory factors, such as CRP, IL-6 and TVF- $\alpha$ [40]. In obese adults, one year of moderate resistance training has been shown to improve the inflammatory factors without affecting cell adhesion molecules [41]. In the present study significant improvement in serum markers of inflammation and cell adhesion was observed after 6 months (data not shown) and 1 year of aerobic training. The results of our study support the hypothesis that 1 year of regular moderate-intensity exercise training in previously sedentary obese adolescents improves the adipose-related pro-inflammatory process. It was also found that this program resulted in a significant increase in the anti-inflammatory molecule adiponectin and a significant reduction in FABP-4, which modulates inflammatory cytokine production in macrophages. It is noteworthy that improvement in serum adipocytokine levels was 
independent of weight loss. With this, others have demonstrated significant increases in serum adiponectin levels after exercise training without changes in body weight or composition [32,42]. Therefore, the hypothesis that significant weight loss (or loss of body fat) is essential to alter adiponectin concentrations has not confirmed.

Regarding adipocyte fatty acid-binding protein (FABP-4), this is the first report, to our knowledge, to characterize the effect of one-year moderate physical activity on serum concentrations of FABP-4 in obese adolescents.

An important limitation of the current study is non-randomized sample. In order to avoid the large drop-out from the study, we allowed the adolescents to choose the type of intervention (exercise vs. diet). It is important to note that most of the adolescent boys have chosen the physical activity as a main therapeutic tool, whereas most of the girls preferred dietary regimen. A second limitation is the small sample size. Additional research will be necessary to confirm our findings in a larger more representative population sample.

The results of this study suggest that regular, moderate-intensity training is an effective non-pharmacologic intervention to attenuate low-grade, systemic inflammation in obese adolescents. Further longterm longitudinal studies are needed to determine whether the exerciseinduced amendment of inflammatory state in obese adolescents results in slower development and/or progression of atherosclerosis.

\section{References}

1. Ogden CL, Carroll MD, Kit BK, Flegal KM (2012) Prevalence of obesity and trends in Body Mass Index among US children and adolescents, 1992-2010. JAMA 307: 483-490.

2. Must A, Jacques PF, Dallal GE, Bajema CJ, Dietz WH (1992) Long-term morbidity and mortality of overweight adolescents. A follow-up of the Harvard Growth Study of 1922 to 1935. N Engl J Med 327: 1350-1355.

3. Fain JN (2010) Release of inflammatory mediators by human adipose tissue is enhanced in obesity and primarily by the nonfat cells: a review. Mediators Inflamm 2010: 513948

4. Visser M, Bouter LM, McQuillan GM, Wener MH, Harris TB (1999) Eleveted C-reactive protein levels in overweight and obese adults. JAMA 282: 2131 2135.

5. Heinrich PC, Castell JV, Andus T (1990) Interleukin-6 and the acute phase response. Biochem J 265: 621-636

6. Blake GJ, Ridker PM (2002) Inflammatory bio-markers and cardiovascular risk prediction. J Intern Med 252: 283-294.

7. Kristiansen OP, Mandrup-Poulsen T (2005) Interleukin-6 and diabetes: the good, the bad, or the indifferent? Diabetes 54: S114-S124.

8. Avogaro A, de Kreutzenberg SV (2005) Mechanisms of endothelial dysfunction in obesity. Clin Chim Acta 360: 9-26.

9. Zhang J, Alcaide P, Liu L, Sun J, He A, et al. (2011) Regulation of endothelia cell adhesion molecule expression by mast cells, macrophages, and neutrophils. PLoS ONE 6: e14525.

10. Guray U, Erbay AR, Guray Y, Yilmaz MB, Boyaci AA, et al. (2004) Levels of soluble adhesion molecules in various clinical presentations of coronary atherosclerosis. Int J Cardiol 96: 235-240.

11. Libby P (2002) Inflammation in atherosclerosis. Nature 420: 868-874.

12. Kapiotis S, Holzer G, Schaller G, Haumer M, Widhalm H, et al. (2006) A proinflammatory state is detectable in obese children and is accompanied by functional and morphological vascular changes. Arterioscler Thromb Vasc Biol 26: 2541-2546.

13. Giordano P, Del Vecchio GC, Cecinati V, Delvecchio M, Altomare M, et al (2011) Metabolic, inflammatory, endothelial and haemostatic markers in a group of Italian obese children and adolescents. Eur J Pediatr 170: 845-850.

14. Montero D, Walther G, Perez-Martin A, Roche E, Vinet A (2012) Endothelial dysfunction, inflammation, and oxidative stress in obese children and adolescents: markers and effect of lifestyle intervention. Obes Rev 13: 441455.

15. Winer JC, Zern TL, Taksali SE, Dziura J, Cali AM, et al. (2006) Adiponectin in childhood and adolescent obesity and its association with inflammatory markers and components of the metabolic syndrome. J Clin Endocrinol Metab 91: 4415-4423

16. Kumada M, Kihara S, Sumitsuji S, Kawamoto T, Matsumoto S, et al. (2003) Association of hypoadiponectinemia with coronary artery disease in men. Arterioscler Thromb Vasc Biol 23: 85-89.

17. Xu A, Wang Y, Xu JY, Stejskal D, Tam S, et al. (2006) Adipocyte fatty acidbinding protein is a plasma biomarker closely associated with obesity and metabolic syndrome. Clin Chem 52: 405-413.

18. Yeung DC, Xu A, Cheung CW, Wat NM, Yau MH, et al. (2007) Serum adipocyte fatty acid-binding protein levels were independently associated with carotid atherosclerosis. Arterioscler Thromb Vasc Biol 27: 1796-1802.

19. Tuncman G, Erbay E, Hom X, De Vivo I, Campos H, et al. (2006) A genetic variant at the fatty acid-binding protein aP2 locus reduces the risk for hypertrigliceridemia, type 2 diabetes, and cardiovascular disease. Proc Nat Acad Sci U S A 103: 6970-6975.

20. Tuomilehto J, Lindstrom J, Eriksson JG, Valle TT, Hamalainen H, et al. (2001) Prevention of type 2 diabetes mellitus by changes in lifestyle among subjects with impaired glucose tolerance. N Engl J Med 344: 1343-1350.

21. Liu K, Daviglus ML, Loria CM, Colangelo LA, Spring B, et al. (2012) Healthy lifestyle through young adulthood and the presence of low cardiovascula disease risk profile in middle age: The coronary artery risk development in (young) adults (CARDIA) study. Circulation 125: 996-1004

22. Reinehr T, de Sousa G, Toschke AM, Andler W (2006) Long-term follow-up of cardiovascular disease risk factors in children after an obesity intervention. Am J Clin Nutr 84: 490-496.

23. Ludwig SD (2012) Weight loss strategies for adolescents: A 14-year-old struggling to lose weight. JAMA 307 (5): 498-508.

24. Daniels SR, Jacobson MS, McCrindle BW, Eckel RH, Sanner BM (2009) American Heart Association Childhood Obesity Research Summit: executive summary. Circulation 119: 2114-2123.

25. Palczewska I, Niedźwiedzka Z (2001) Somatic development indices in children and youth of Warsaw. Med Wieku Rozwoj 5: 18-118.

26. Nawarycz T, Ostrowska-Nawarycz L (2007) Percentile distributions of wais circumference in children and adolescents. Pediatr Pol 82: 418-424.

27. Matthews DR, Hosker JP, Rudenski AS, Naylor BA, Treacher DF, et al. (1985) Homeostasis model assessment: insulin resistance and beta-cell function from fasting plasma glucose and insulin concentrations in man. Diabetologia 28: 412-419.

28. Balagopal P, George D, Patton N, Yarandi H, Roberts WL, et al. (2005) Lifestyle-only intervention attenuates the inflammatory state associated with obesity: a randomized controlled study in adolescents. J Pediatr 146: 342-348.

29. Roth CL, Kratz M, Ralston MM, Reinehr T (2011) Changes in adipose-derived inflammatory cytokines and chemokines after successful lifestyle intervention in obese children. Metabolism 60: 445-452.

30. Roberts CK, Chen AK, Barnard RJ (2007) Effect of a short-term diet and exercise intervention in youth on atherosclerotic risk factors. Atherosclerosis 191: 98-106.

31. Kim JA, Montagnani M, Koh KK, Quon MJ (2006) Reciprocal relationships between insulin resistance and endothelial dysfunction: molecular and pathophysiological mechanisms. Circulation 113: 1888-1904.

32. Tjonna AE, Stolen TO, Bye A, Volden M, Slordahl SA, et al. (2009) Aerobic interval training reduces cardiovascular risk factors more than a multitreatment approach in overweight adolescents. Clin Sci (Lond) 116: 317-326.

33. Brambilla P, Pozzobon G, Pietrobelli A (2011) Physical activity as the main therapeutic tool for metabolic syndrome in childhood. Int J Obes 35: 16-28.

34. Harmse B, Kruger HS (2010) Significant differences between serum CRP levels in children in different categories of physical activity: the PLAY study. Cardiovasc J Afr 21: 316-322.

35. Balagopal PB, Gidding SS, Buckloh LM, Yarandi HN, Sylvester JE, et al. (2010) 
Citation: Garanty-Bogacka B, Rac M, Syrenicz M, Gebala A, Walczak M, et al. (2012) Changes in Serum Adipocytokines and Inflammatory Biomarkers Following One-Year of Exercise Training in Obese Adolescents. J Diabetes Metab 3: 212. doi:10.4172/2155-6156.1000212

Changes in circulating satiety hormones in obese children: a randomized controlled physical activity-based intervention study. Obesity (Silver Spring) 18: $1747-1753$.

36. Meyer AA, Kundt G, Lenschow U, Schuff-Werner P, Kienast W (2006) Improvement of early vascular changes and cardiovascular risk factors in obese children after a six-month exercise program. J Am Coll Cardiol 48: 1865-1870.

37. Watts K, Beye P, Siafarikas A, Davis EA, Jones TW (2004) Exercise training normalizes vascular dysfunction and improves central adiposity in obese adolescents. J Am Coll Cardiol 43: 1823-1827.

38. Farpour-Lambert NJ, Aggoun Y, Marchand LM, Martin XE, Herrmann FR, et al. (2009) Physical activity reduces systemic blood pressure and improves early markers of atherosclerosis in pre-pubertal obese children. J Am Coll Cardiol 54: 2396-2406.
39. Kelly AS, Steinberger J, Olson TP, Dengel DR (2007) In the absence of weight loss, exercise training does not improve adipokines or oxidative stress in overweight children. Metabolism 56: 1005-1009.

40. Goldhammer E, Tanchilevitch A, Maor I, Beniamini Y, Rosenschein U, et al (2005) Exercise training modulates cytokines activity in coronary heart disease patients. Int J Cardiol 100: 93-99.

41. Olson TP, Dengel DR, Leon AS, Schmitz KH (2007) Changes in inflammatory biomarkers following one-year of moderate resistance training in overweight women. Int J Obes (Lond) 31: 996-1003.

42. Kriketos AD, Gan SK, Poynten AM, Furler SM, Chisholm DJ, et al. (2004) Exercise increases adiponectin levels and insulin sensitivity in humans. Diabetes Care 27: 629-630. 